\title{
Amino acids in atmospheric droplets: perturbation of surface tension and critical supersaturation predicted by computer simulations
}

X. $\mathrm{Li}^{1,3}$, T. Hede ${ }^{2}$, Y. Tu ${ }^{1}$, C. Leck ${ }^{2}$, and H. Ågren ${ }^{1}$

${ }^{1}$ Department of Theoretical Chemistry and Biology, School of Biotechnology, Royal Institute of Technology, 10691 Stockholm, Sweden

${ }^{2}$ Department of Meteorology, Stockholm University, 10691 Stockholm, Sweden

${ }^{3}$ Laboratory for Advanced Materials and Institute of Fine Chemicals, East China University of Science and Technology, Shanghai 200237, China

Received: 15 October 2011 - Accepted: 26 October 2011 - Published: 18 November 2011 Correspondence to: T. Hede (hede @ misu.su.se)

Published by Copernicus Publications on behalf of the European Geosciences Union.
Amino acids in atmospheric droplets

X. Li et al.

Title Page
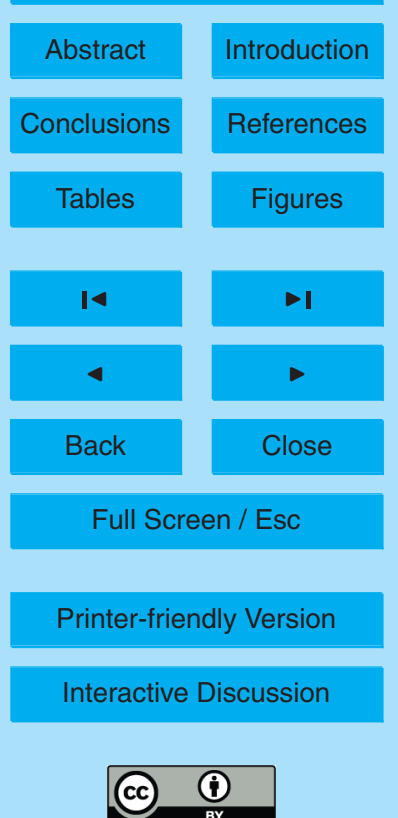


\section{Abstract}

Atmospheric amino acids constitute an important fraction of the water-soluble organic nitrogen compounds in both marine and continental aerosols, and have been confirmed as effective cloud condensation nuclei materials in laboratory tests. We here 5 present a molecular dynamics study of amino acids representative for the remote marine atmospheric aerosol-cloud system, in order to investigate molecular distributions, orientations and induced changes in surface tension, and to evaluate their indirect effects on optical properties of clouds. These L-amino acids, including serine, glycine, alanine, valine, methionine and phenylalanine, are categorized as hydrophilic and hydrophobic according to their affinities to water. Different amino acids show distinct effects on the surface tension; even the same amino acid has different influence on the surface tension for planar and spherical interfaces. The curvature dependence of the surface tension is modelled by a quadratic polynomial function of the inverse of droplet radius, and such relationship is used to improve the Köhler equation in predicting the critical water vapour supersaturation of the droplet activation.

\section{Introduction}

Clouds, which are collections of small water drops or ice crystals in the atmosphere, reflect and scatter incoming solar radiation and absorb outgoing heat radiation from Earth, and for this reason play a major role in Earth's weather and climate. The extensive marine stratiform cloud decks that cover the oceans of the world are poorly understood and are a large uncertainty for climate models (Solomon et al., 2007). Major improvement to our understanding of climate depends on a better understanding of these marine clouds (Wine, 2010). Cloud droplet activation starts when water vapour condenses on an airborne aerosol particle, called a cloud condensation nuclei or CCN particles determine the number and sizes of cloud drops, and also cloud properties

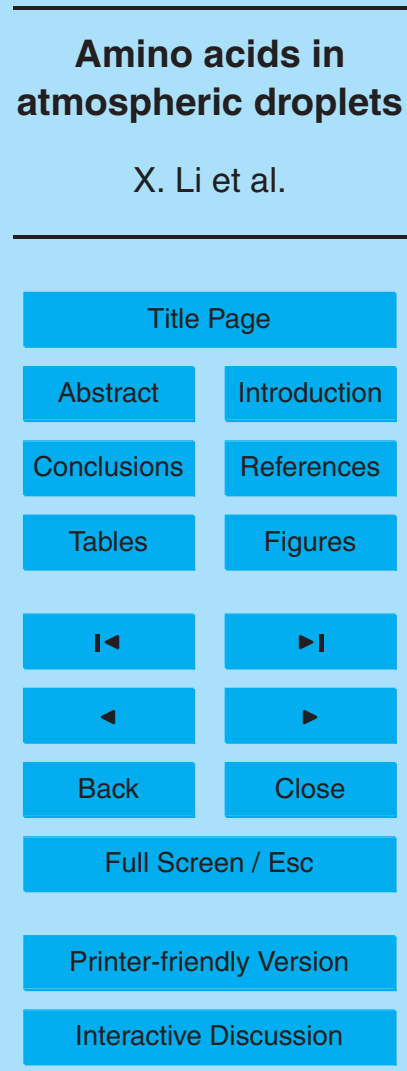


such as water content.

The process in which water vapour condenses and forms liquid cloud drops is based on equilibrium thermodynamics and was first formulated by Köhler in 1936 (Köhler, 1936). It combines the Kelvin effect, which describes the change in saturation vapour 5 pressure due to a curved surface and is related to the ability of the CCN to reduce droplet surface tension through the presence of surfactants, and Raoult's Law, which relates the saturation vapour pressure to the solute. The water vapour supersaturation at which the drop will grow without bound is called the critical supersaturation. The diameter at which this happens is called the critical diameter. Recently it has been sug10 gested that the presence of atmospheric surfactants in CCN could reduce the vapour pressure of water over a solution droplet and result in an increase in the population of cloud droplets with smaller size and hence change the microphysical properties of clouds in making them reflecting incoming solar radiation more efficiently (Facchini et al., 1999).

15 Typical levels of amino acid molecules as water-soluble organic nitrogen (WSON) compounds found in marine rain (Mopper and Zika, 1987) showed enrichment by two orders of magnitude over typical seawater values. Spitzy (1990) reported amino acid data from size fractionated aerosol collected in the northern Indian Ocean. He found a several-fold enrichment of amino acid nitrogen in the submicrometer size fraction over the coarse fraction. Moreover, production of amino acids from proteins and bacteria has been identified in Antarctic cloud water (Saxena, 1983). Blanchard and co-worker (Blanchard, 1971; Blanchard and Syzdek, 1988) have long advocated that a significant proportion of the remote oceanic aerosol is derived from bubble bursting. The bubbles result from entrainment of air induced by wind stress at the air-water interface, which produces primary aerosol particles in CCN sizes. In this process, bubbles scavenge not only sea-salt but also microorganisms and water soluble organic surface-active compounds such as the WSON (Kuznetsov et al., 2005), as they rise through the water prior to their injection into the atmosphere. That the amino acids can behave as effective CCN has been confirmed by laboratory measurements (Kristensson et al.,
ACPD

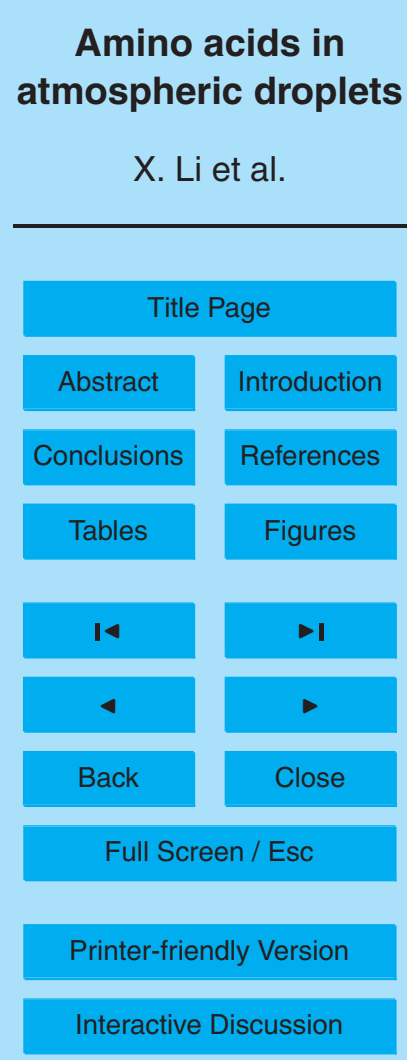

30921 
2010). In addition to the above reports on WSON specific L-amino acids have been identified in marine atmospheric samples, including alanine, arganine, glycine, phenylalanine, proline, serine, and valine (Mace et al., 2003a-c; Wedyan and Preston, 2008; Zhang and Anastasio, 2003; Malder et al., 2004).

5 A versatile theoretical approach to investigate liquid-gas interfaces at the molecular level is the molecular dynamics (MD) simulation technique, which has become more and more useful due to the fast development of algorithms and computers. Starting from the pioneer paper by Alejandre et al. (1995) MD simulations on surface tension have been extensive for planar liquid-gas interfaces (Yeh and Berkowitz, 1999; Ismail 10 et al., 2006; Klauda et al., 2007; Chen and Smith, 2007; Yuet and Blankschtein, 2010). However, theoretical studies on spherical interfaces are relatively limited (Thompson et al., 1984; Zakarov et al., 1997; van Giessen and Blokhuis, 2009; Sampayo et al., 2010). Our previous work in this area has concerned MD studies on spherical liquidgas interfaces of atmospheric droplets (Li et al., 2010, 2011).

15 In this paper, we continue our work by employing the MD simulation technique to study atmospheric water droplets containing six types of L-amino acids: serine (SER), glycine (GLY), alanine (ALA), valine (VAL), methionine (MET) and phenylalanine (PHE). All these amino acids except methionine have been found in both marine and continental aerosol samples (Mace et al., 2003a-c; Wedyan and Preston, 2008; Zhang and 20 Anastasio, 2003; Malder et al., 2004). However, over the central Arctic Ocean, when organic material was found to be present in film droplets associated with bubble bursting, L-methionine of biological origin was suggested to be responsible for observed periods of new particle formation (Leck and Bigg, 1999). Laboratory experiments showed that L-methionine can form freshly nucleated particles (Leck and Bigg, 1999). However, 25 a verification of this particle formation route in the Arctic is still missing. L-methionine has an important role in the production of dimethyl-sulfoniopropionate (DMSP), an osmo-, cryo-, and light-protecting agent in marine algae (Karsten et al., 1992). The chemical structures of the six L-amino acids are shown in Fig. 1. For each type of amino acid, the molecular distribution and orientation in the droplets are analyzed,

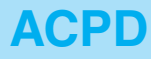

11, 30919-30947, 2011

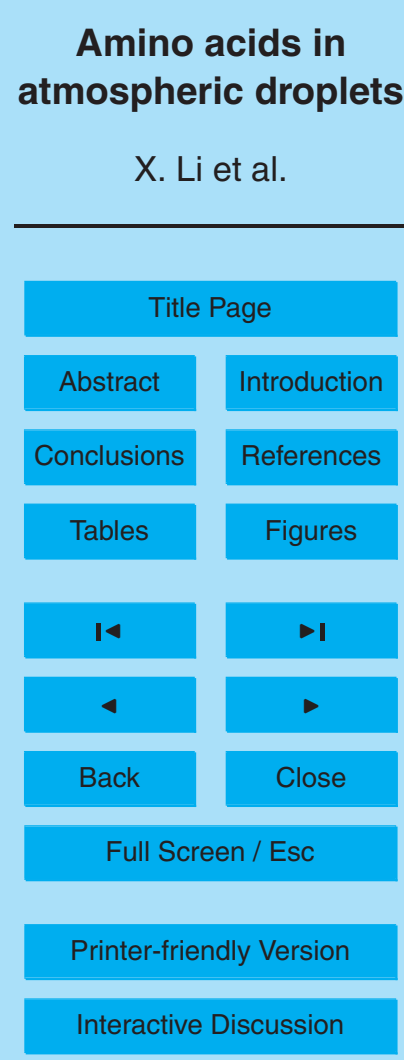

30922 
spherical and planar liquid-gas interfaces investigated, the surface tension calculated, and the curvature dependence of the surface tension formulated. The change of surface tension induced by the presence of amino acids is also discussed in the framework of Köhler theory (Köhler, 1936). We would like to point out that various ions exist in 5 seawater and therefore will likely occur in cloud droplets, and these ions may alter the hydrogen bonding network along with the amino acids and perhaps the distribution of the amino acid molecules within the droplet. However, we did not include ions in our study because we wish to identify the separate role of each amino acid in forming cloud water droplets. With ions excluded we can obtain a clear relation between the property 10 and structure of each amino acid with that of the cloud water droplet. This will help the analysis of the droplet behaviour when the amino acids are mixed with each other and with ions sourced from seawater.

\section{Computational methods}

\subsection{Surface tension calculations}

15 The surface tension for liquid-gas interfaces can be categorized into two cases, the spherical interface of liquid droplet and the planar interface of a liquid slab, which require different methodologies for their study. The surface tension for planar liquid-gas interfaces is usually divided into two contributions, the original part $\sigma_{\mathrm{o}}$ and the dispersion correction $\sigma_{\mathrm{d}}$. The original part can be calculated from the diagonal components

$\sigma_{0}=\frac{1}{2} L_{z}\left[P_{z z}-\frac{1}{2}\left(P_{x x}+P_{y y}\right)\right]$

and the dispersion correction is

$\sigma_{d}=12 \pi \varepsilon \sigma^{6}\left(\rho_{\alpha}-\rho_{\beta}\right)^{2} \int_{0}^{1} \mathrm{~d} s \int_{r_{c}}^{\infty} \mathrm{d} r\left(3 s^{3}-s\right) r^{-3} \operatorname{coth}\left(\frac{r s}{\xi}\right)$

\section{ACPD}

11, 30919-30947, 2011

Amino acids in atmospheric droplets

X. Li et al.

Title Page

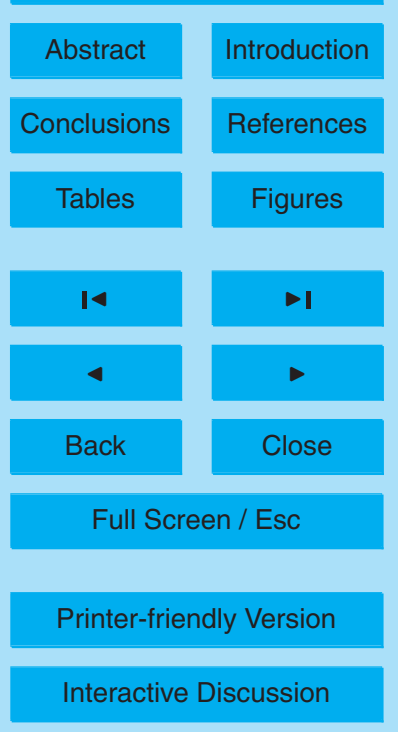




$$
=12 \pi \varepsilon \sigma^{6}\left(\rho_{\alpha}-\rho_{\beta}\right)^{2} \int_{0}^{1} \mathrm{~d} s \int_{0}^{1 / r_{c}} \mathrm{~d} r^{\prime}\left(3 s^{3}-s\right) r^{\prime} \operatorname{coth}\left(\frac{s}{r^{\prime} \xi}\right)
$$

where the substitution $r^{\prime}=r^{-1}$ has been used to perform the double integration on finite intervals. For liquid mixtures, an average value of $\varepsilon \sigma^{6}$ is used as described in our previous paper (Li et al., 2011). The liquid density $\rho_{\alpha}$, gas density $\rho_{\beta}$ and fitting 5 parameter $\xi$ are obtained from hyperbolic tangent fitting of the number density profile along the $z$-axis

$\rho(z)=\frac{1}{2}\left(\rho_{\alpha}+\rho_{\beta}\right)-\frac{1}{2}\left(\rho_{\alpha}-\rho_{\beta}\right) \tanh \left(\frac{z-z_{0}}{\xi}\right)$

The surface tension of spherical interfaces can be evaluated from the Irving-Kirkwood pressure tensor as demonstrated in previous papers (Thompson et al., 1984; Zakarov 10 et al., 1997; Li et al., 2010, 2011). The idea of the method is to compute the approximate surface tension from the work of formation and the radius of the droplet

$\sigma \approx \tilde{\gamma}_{\mathrm{e}}=\frac{3 W}{4 \pi R_{\mathrm{e}}^{2}}$

where $\tilde{\gamma}_{\mathrm{e}}$ is the so-called effective surface tension and has been proved to properly describe the surface tension of atmospheric droplets (Li et al., 2010, 2011).

By using molecular dynamics simulation techniques it is convenient to obtain the radial number density profile which can be fitted to the hyperbolic tangent function, and the radius of the equimolar surface is then derived from the fitted densities of the liquid phase $\alpha$ and the gas phase $\beta$

$$
\begin{aligned}
& \rho(r)=\frac{1}{2}\left(\rho_{\alpha}+\rho_{\beta}\right)-\frac{1}{2}\left(\rho_{\alpha}-\rho_{\beta}\right) \tanh \left(\frac{r-r_{0}}{\xi}\right) \\
& R_{\mathrm{e}}^{3}=-\frac{1}{\rho_{\alpha}-\rho_{\beta}} \int_{0}^{\infty} r^{3} \frac{\mathrm{d} \rho(r)}{\mathrm{dr}} \mathrm{d} r
\end{aligned}
$$

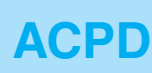

11, 30919-30947, 2011

\section{Amino acids in atmospheric droplets}

X. Li et al.

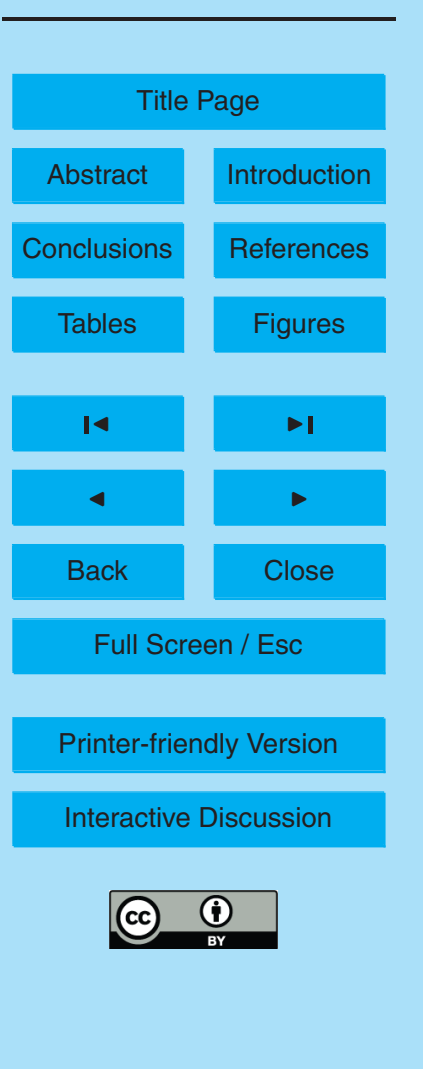


The work of formation is computed from the normal component of the Irving-Kirkwood pressure tensor, $P_{\mathrm{N}}(r)$. The profile of $P_{\mathrm{N}}(r)$ is obtained as the sum of the kinetic term, which is dependent on the radial density and the temperature, and the potential term, which is computed from intermolecular forces

${ }_{5} \quad P_{\mathrm{N}}(r)=P_{\mathrm{K}}(r)+P_{U}(r)=k_{\mathrm{B}} T \rho(r)+S^{-1} \sum_{k} f_{k}$

$W=2 \pi \int_{0}^{R_{\beta}}\left[P_{\mathrm{N}}(r)-P_{\beta}\right] r^{2} \mathrm{~d} r=2 \pi \int_{0}^{R_{\beta}} P_{\mathrm{N}}(r) r^{2} \mathrm{~d} r-\frac{2 \pi}{3} P_{\beta} R_{\beta}^{3}$

\subsection{Molecular dynamics simulations}

The planar liquid-gas interface was first set up for investigations through MD simulations. For each type of amino acid, a cubic simulation box was constructed and 10 filled with 10 amino acid molecules and 1000 water molecules, and then the box was elongated three times along the $z$-axis to create the planar liquid-gas interfaces. Afterwards, more systems were set up to model the surface tension of spherical liquid-gas interfaces for droplets. For each type of amino acid, three cubic boxes were set up and filled with 10 amino acid molecules +1000 water molecules, 20 amino acid molecules 15 +2000 water molecules, and 50 amino acid molecules +5000 water molecules, respectively. Each box was then enlarged in three dimensions so that the length of the box was $6.0 \mathrm{~nm}$ longer than the diameter of the droplet, in order to minimize the interaction between the droplet and its periodic images. Here the diameter of the droplet was estimated from the volume of the initial cubic box. The concentration of amino acids in the droplet in this study $\left(0.56 \mathrm{moll}^{-1}\right)$ is a bit high compared with the typical values in marine rain, due to the fact that the number of water molecules in a droplet which can be simulated is limited by our currently available computer resources. In order to obtain statistically reliable results with limited simulation time, we therefore increased slightly the number of amino acids in each cluster so that the statistical error due to the limited time of simulations could be diminished.

30925
11, 30919-30947, 2011

\section{Amino acids in atmospheric droplets \\ X. Li et al.}

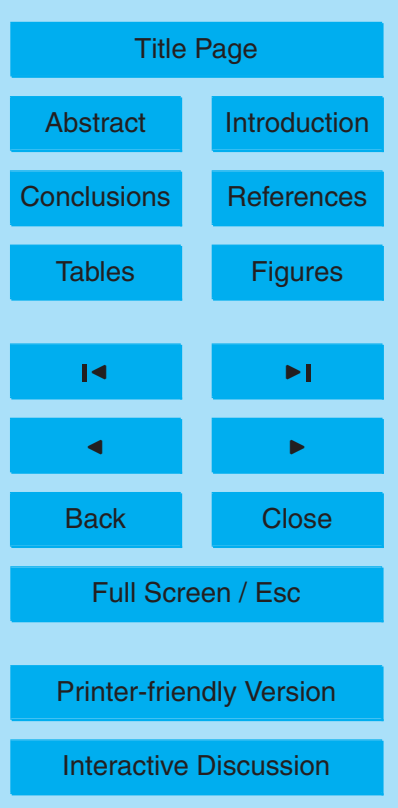


The GROMACS program package (version 4.5.2) (van der Spoel et al., 2005; Hess et al., 2008) was used to carry out the molecular dynamics simulations. The SPC/E (extended simple point charge) water model (Berendsen et al., 1987) was employed, with the two $\mathrm{O}-\mathrm{H}$ bond lengths constrained at $1.0 \AA$ by the LINCS (linear constraint 5 solver) algorithm (Hess et al., 1997; Hess, 2008) and the $\mathrm{H}-\mathrm{O}-\mathrm{H}$ angle kept flexible. The OPLS (optimized potentials for liquid simulations) all-atom force field (Jorgensen et al., 1996) was used to model the amino acid molecules, with the bonds containing $\mathrm{H}$ atoms constrained by the LINCS algorithm (Hess et al., 1997; Hess, 2008). All simulations were performed in canonical (constant-NVT) ensembles, with the temperature 10 maintained at 298 Kelvin by the Nosé-Hoover thermostat (Nosé, 1984; Hoover, 1985). Periodic boundary conditions were applied during the simulations. The van der Waals interaction was modelled by the Lennard-Jones potential truncated at the cutoff radius of $10 \AA$. The Coulomb interaction was evaluated by the Ewald summation, where the real part of the potential is truncated at $10 \AA$ and the reciprocal interaction is calculated by the SPME (smoothed particle mesh Ewald) (Darden et al., 1993; Essmann et al., 1995) method with a mesh of reciprocal vectors of $1.2 \AA$ in every direction and a spline of the order of 4 . The time step of the simulations was set to $2 \mathrm{fs}$. Each system was subject to energy minimization and then a $3 \mathrm{~ns}$ simulation to reach equilibrium, and another $2 \mathrm{~ns}$ simulation was carried out with trajectories saved every $0.2 \mathrm{ps}$ for further 20 analysis.

With the MD simulations completed and the trajectories recorded, molecular distributions and orientations of the amino acids were analyzed. Surface tension calculations were also performed for both planar and spherical interfaces as described previously. The curvature dependence of the droplet surface tension was fitted to a quadratic polynomial function of the inverse of the droplet radius, and the Köhler theory was applied to gain insight into the effects of amino acids on the nucleation and growth of aerosol droplets. According to the Köhler theory (Köhler, 1936), the supersaturation is determined from two competing terms; the Kelvin term, which is related to the curvature and surface tension of the droplet, can decrease the ability of droplet nucleation, while the

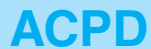

11, 30919-30947, 2011

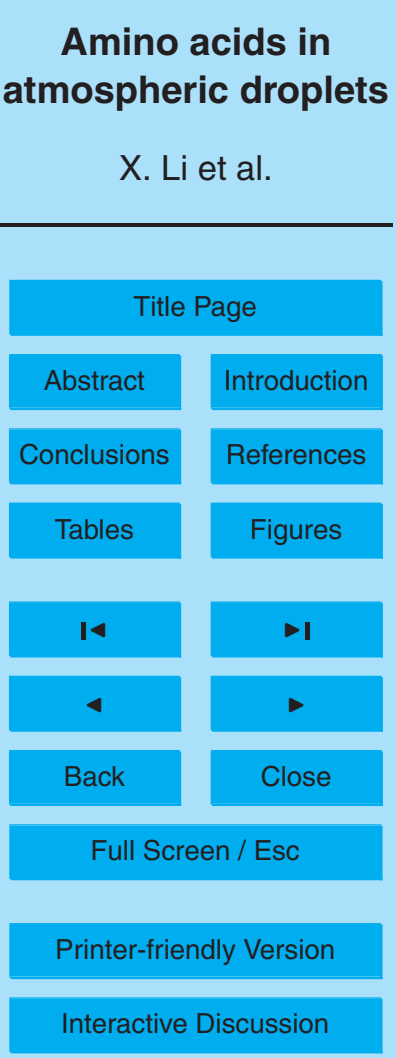

30926 
Raoult term increases the ability for droplet growth due to the solvation of aerosol components inside the droplet. Specifically, an increase in the surface tension is expected to increase the critical supersaturation at which the droplet is activated.

\section{Results and discussion}

\section{3.1 Surface tension for planar interfaces}

Table 1 lists the calculated surface tension values for planar interfaces. The slope of surface tension with respect to concentration, $d \sigma / d C$ in $\mathrm{mJ} \mathrm{m}^{-2} \mathrm{Imol}^{-1}$, is evaluated from the concentration of 10 amino acid molecules in 1000 water molecules, which is equal to $0.56 \mathrm{moll}^{-1}$. It can be seen that SER, GLY and ALA are able to increase 10 the surface tension of the planar liquid-gas interface, while VAL, MET and PHE can decrease the surface tension, in qualitative agreement with experimental observations (Pappenheimer et al., 1936; Bull and Breese, 1974). Although the computed $d \sigma / d C$ values of the amino acids differ from experimental results, it should be noted that the measurements in Bull and Breese (1974) are performed in salt solution, where the $15 \mathrm{Na}^{+}$and $\mathrm{Cl}^{-}$ions might influence the surface tension. A comparison between the $z-$ axial number densities of the amino acids is presented in Fig. 2. It can be seen that SER, GLY and ALA tend to stay in the bulk phase of the solution, while VAL, MET and PHE show sharp peaks at the surface. Still, the hydrophobic VAL molecules have the chance to stay in the bulk solution, probably due to the limited surface-area-to-volume

\subsection{Water droplets containing different amino acids}

Figure 3a shows the snapshots for water droplets containing 5000 water molecules and different amino acids: SER, GLY, ALA, VAL, MET and PHE. Among these amino acids, the former three ones are hydrophilic and stay inside the droplets, while the latter

\section{1, 30919-30947, 2011}

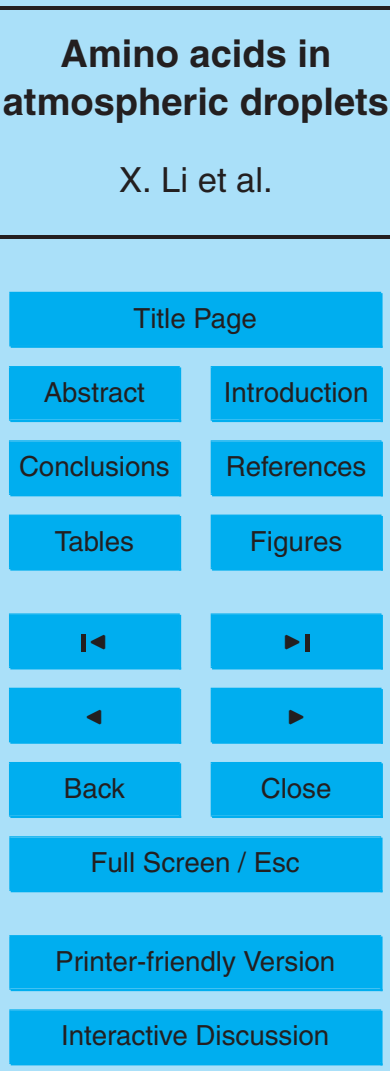


three ones are hydrophobic and tend to concentrate on the droplet surface. Although ALA has a hydrophobic methyl group as side-chain, the whole molecule still shows hydrophilicity due to the presence of the $-\mathrm{NH}_{3}^{+}$and the $-\mathrm{COO}^{-}$ions. Besides, it is interesting to observe that PHE molecules are able to form an ordered structure on the 5 droplet surface, which is very stable during the simulation. A close view is shown in Fig. $3 b$, in which the hydrogen bond network among the phenylalanine molecules is presented.

Further insight can be obtained from the radial number densities of the amino acids, as shown in Fig. 4a, where SER, GLY and ALA have notable radial densities inside the 10 droplet, while the peak densities for VAL, MET and PHE appear on the droplet surface. GLY shows a much larger radial number density than SER and ALA in the region of $0.0<r<0.5 \mathrm{~nm}$, however, this region lacks statistics due to its small volume and gives limited information about the distribution of the amino acid molecules. SER has a clear density peak between radii of 0.5 and $1.0 \mathrm{~nm}$, indicating its strong hydrophilicity. ALA shows a higher density than GLY and SER in the region of $2.0<r<2.5 \mathrm{~nm}$, which can be attributed to the presence of the hydrophobic methyl group which drags the ALA molecules towards the droplet surface. Moreover, it is interesting to examine the orientation of the amino acid molecules in the droplets. Figure $4 \mathrm{~b}$ illustrates the radial number densities of the backbone and side-chain parts of the two amino acids, SER and VAL. For the hydrophilic SER, no significant preference of molecular orientation is found. The number densities of the backbone and side-chain of the molecule leapfrog over each other along the radius axis, reflecting the thermodynamic motions of the SER molecules inside the droplet. On the contrary, for VAL a clear molecular orientation is observed on the surface, with the hydrophilic backbone staying inside and the hydrophobic side-chain pointing outward.

The orientation of amino acid molecules can also be reflected by the order parameter $\left\langle 3 \cos ^{2} \theta-1\right\rangle / 2$ which characterizes the degree of order of a system. Here $\theta$ is defined as the angle between the two vectors, $O \rightarrow C_{\alpha}$ and $C_{\alpha} \rightarrow C_{\beta}$, where $O$ denotes the geometrical center of the droplet, and $C_{\alpha}$ and $C_{\beta}$ are the $\alpha$-carbon and $\beta$-carbon
ACPD

\section{Amino acids in atmospheric droplets}

X. Li et al.

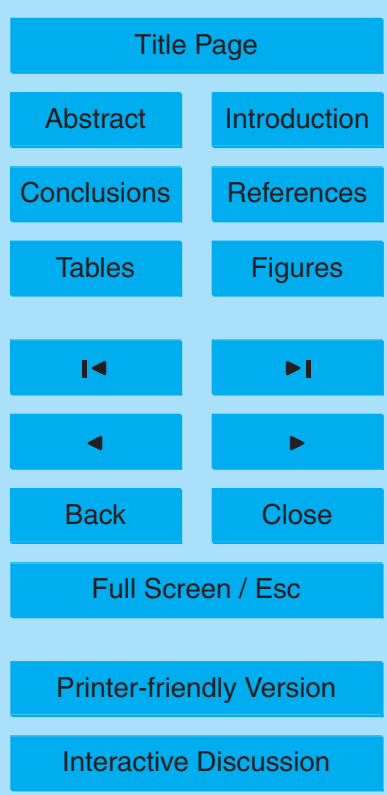


atoms in the amino acid molecule, respectively. For GLY, $C_{\beta}$ is represented by one hydrogen atom on $C_{\alpha}$. The computed order parameters are listed in Table 2. Not surprisingly, the order parameters of both SER and GLY are very close to zero, indicating that there is little correlation between the radial vector and the orientation of 5 the amino acid molecules. The order parameter of ALA is slightly larger than those of SER and GLY, reflecting the weak preference of orientation caused by the hydrophobic effect of the methyl group. The hydrophobic VAL, MET and PHE have much larger order parameters, the largest value of 0.5209 suggesting that PHE has the strongest hydrophobicity.

10 The computed normal components of Irving-Kirkwood pressure tensors of water droplets containing 5000 water molecules and different amino acids are shown as $P_{\mathrm{N}}(r)$ curves in Fig. 5a. In the $P_{\mathrm{N}}(r)$ profile of each droplet, a peak appears at the surface, indicating the presence of surface tension. A difference can found at the height of the peak, which is less than $50 \mathrm{~kJ} \mathrm{~mol}^{-1} \mathrm{~nm}^{-3}$ for SER, GLY and ALA and close to $1555 \mathrm{~kJ} \mathrm{~mol}^{-1} \mathrm{~nm}^{-3}$ for VAL, MET and PHE. Since the work of formation is computed from the integrand $P_{\mathrm{N}}(r) r^{2}$, variation in $P_{\mathrm{N}}(r)$ value at large $r$ will give rise to a large difference in the work of formation and hence the surface tension. A direct comparison between the $P_{\mathrm{N}}(r)$ curves of SER and VAL is shown in Fig. 5b, where the $P_{\mathrm{N}}(r)$ curve for pure water is also presented as a dashed line. The hydrophilic SER molecules where $r$ is around $1.0 \mathrm{~nm}$. Although the $P_{\mathrm{N}}(r)$ value for droplets containing SER is enhanced when $r$ is smaller than $0.5 \mathrm{~nm}$, comparing with that of pure water, it does not contribute much to the work of formation due to the small value of $r$. On the contrary, the hydrophobic VAL perturbs the $P_{\mathrm{N}}(r)$ curve at the surface where $r$ is large, and has less notable effect on the $P_{\mathrm{N}}(r)$ curve at smaller $r$. The $\Delta P_{\mathrm{N}}(r)$ curves are also plotted in Fig. $5 \mathrm{~b}$ as the difference between the $P_{N}(r)$ values of the droplet containing amino acid and the pure water droplet. In the surface region where $r$ is between $2.5 \mathrm{~nm}$ and $3.5 \mathrm{~nm}$, SER has an undulate effect on the $P_{\mathrm{N}}(r)$ curve which is similar to GLY (Li et al., 2011), while the presence of VAL results in a positive peak. From Eqs. (4) and (8) we
ACPD

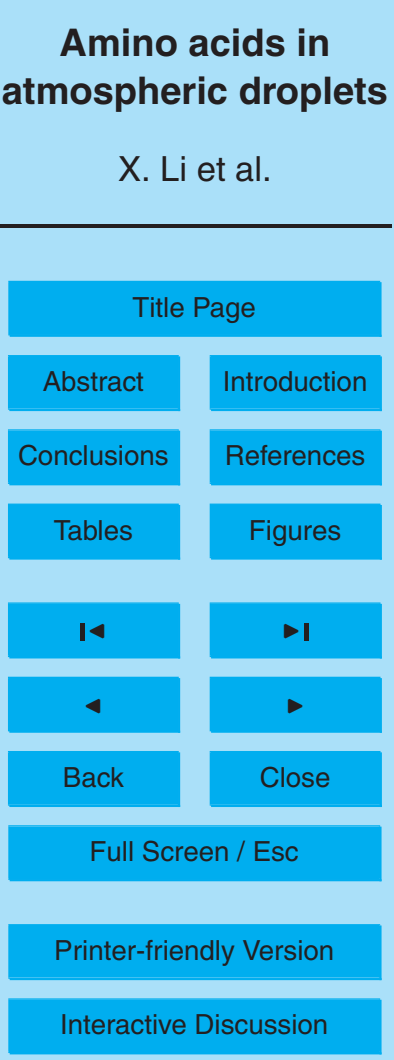


see that the magnitude of surface tension is dependent on the integration over $P_{\mathrm{N}}(r) r^{2}$; therefore VAL is expected to increase the surface tension of the droplet. Although hydrophobic amino acids have similar structures to surfactants such as cis-pinonic acid (Li et al., 2010), they have different effects on the surface tension of droplets.

\subsection{Curvature dependence of surface tension and correction to the Köhler equation}

Previous experience has shown that the curvature dependence of surface tension can be modelled by a quadratic relationship between the surface tension $\sigma$ and the inverse of droplet radius $R_{\mathrm{e}}$, with planar interface regarded as spherical interface with 10 infinite radius ( $\mathrm{Li}$ et al., 2011). The fitted curves for the six types of amino acids are in the form $\sigma=c_{0}+c_{1} / R_{\mathrm{e}}+c_{2} / R_{\mathrm{e}}^{2}$, and are plotted in Fig. 6 , with the coefficients $c_{0}$, $c_{1}$ and $c_{2}$ listed in Table 3. Here $R_{\mathrm{e}}$ is the radius of the droplet (in $\mathrm{nm}$ ) and $\sigma$ is the surface tension (in $\mathrm{mJ} \mathrm{m}^{-2}$ ). Note that the equations for amino acids are valid at the concentration of $0.56 \mathrm{moll}^{-1}$. By shifting the value of $\sigma_{W}$ at infinite $R_{\mathrm{e}}$ to ex15 perimental value (Kristensson, 2010) of $72.4 \mathrm{~mJ} \mathrm{~m}^{-2}$ and assuming that the amino acid-induced deviation in surface tension depends linearly on the concentration, as observed in experiments (Pappenheimer et al., 1936; Bull and Breese, 1974) we can obtain the formula for evaluating the surface tension of droplet containing amino acid as $\sigma=\sigma_{W}+\left[\left(c_{0}-65.45\right)+\left(c_{1}-50.66\right) / R_{\mathrm{e}}+\left(c_{2}+100.00\right) / R_{\mathrm{e}}^{2}\right] \times C / 0.56$, where $C$ is the concentration of the amino acid in $\mathrm{molI}^{-1}$, and $\sigma_{W}=72.4+50.66 / R_{\mathrm{e}}-100.00 / R_{\mathrm{e}}^{2}$.

A useful formula of the Köhler theory is expressed as (Bilde and Svenningsson, 2004; Rosenørn et al., 2006).

$s \equiv \frac{p}{p_{0}}=a_{\mathrm{w}} \exp \left(\frac{4 M_{\mathrm{w}} \sigma}{R T \rho D_{p}}\right)$

where $s$ is the saturation ratio, $p$ is the vapour pressure of water over a droplet, $p_{0}$ is the water vapour pressure over a flat surface of pure water, $a_{\mathrm{w}}$ is the water activity of the 30930
11, 30919-30947, 2011

Amino acids in atmospheric droplets

X. Li et al.

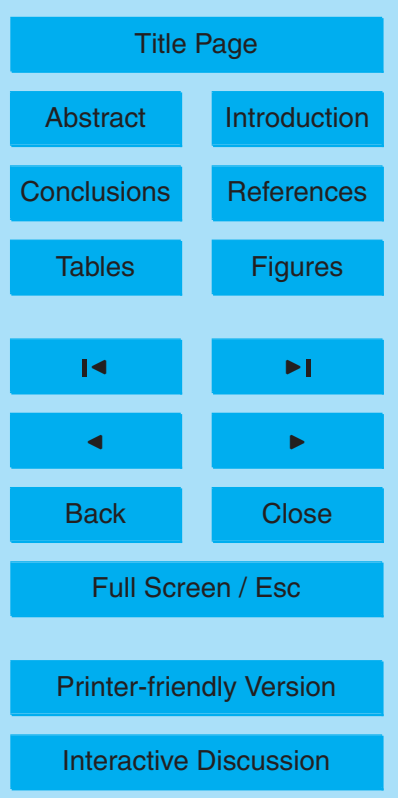


solution, $M_{\mathrm{w}}$ is the molar mass of water, $\sigma$ is the surface tension, $R$ is the gas constant, $T$ is the temperature, $\rho$ is the density of the solution, and $D_{p}$ is the droplet diameter. The water vapour supersaturation, which is of interest in the activation processes of aerosol particles, is equal to $s-1$. Figure 7 shows the Köhler curves for dry amino acid particles 5 with diameters of $50 \mathrm{~nm}$, from which the critical supersaturation can be determined as the peak supersaturation. All parameters except the droplet surface tension were taken from the paper by Kristensson et al. (2010). By applying surface tension correction to the Köhler curves, the critical supersaturations are slightly increased for all the six types of amino acids, and therefore in better agreement with experimental results for GLY and 10 SER (Kristensson et al., 2010). The predicted critical water vapour supersaturations are listed in Table 4.

It should be noted that we did not take into account the limited solubility of the amino acids in this work. According to the experimental results by Kristensson et al. (2010), most amino acids act as if they are fully water-soluble, except for L-methionine and Ltyrosine. Moreover, in real atmospheric particles the proportion of amino acids would be low enough (for instance $<20 \%$ ) for them to act as fully soluble components and effective CCN materials (Kristensson et al., 2010). Therefore, we here disregard the factor of limited solubility and focus on the surface tension correction to the Köhler curves. Somewhat surprisingly, all the six amino acids studied in this work show positive effects on the water vapour critical supersaturation, regardless of their hydrophilicity or hydrophobicity. The reason is that the surface tension of a droplet is enhanced by its curvature, according to the quadratic dependence on the inverse of droplet radius, while the decrease of surface tension induced by the presence of hydrophobic amino acids cannot match the former effect. As a result, the slightly enhanced sur25 face tension will increase the critical water vapour supersaturation for activation, which could (at least partially) explain the underpredicted critical supersaturation of the mixed particles containing L-tyrosine or L-methionine by Köhler theory.

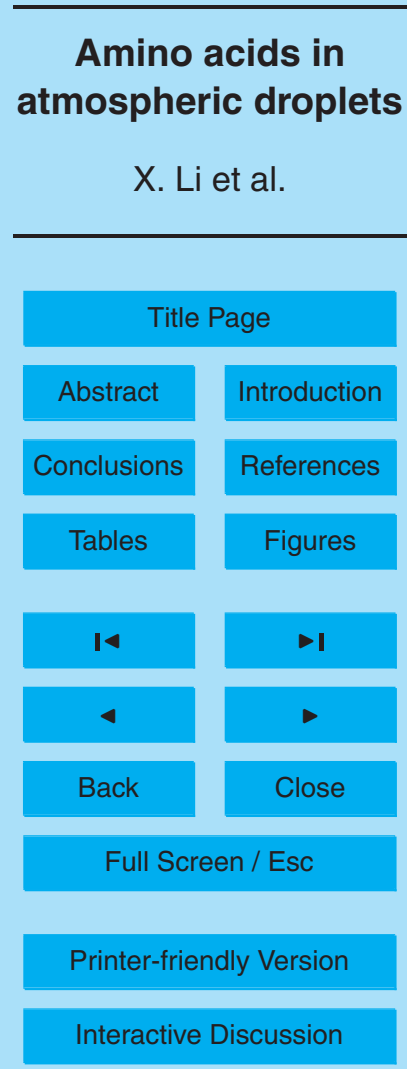




\section{Conclusions}

We have presented molecular dynamics simulation studies on atmospheric droplets containing L-amino acids: serine, glycine, alanine, valine, methionine and phenylalanine. The simulation results show that the former three amino acids are hydrophilic 5 while the latter three ones are hydrophobic, according to the radial distribution of the molecules in droplets. The hydrophilic amino acids tend to stay in the bulk of the droplet, while the hydrophobic amino acids are found to concentrate on the surface, with the hydrophilic $-\mathrm{NH}_{3}^{+}$and $-\mathrm{COO}^{-}$groups staying inside the droplet and the hydrophobic side-chain pointing outward. For droplets containing 5000 water molecules and 50 amino acid molecules, the perturbations on surface tension induced by hydrophilic amino acids are relatively small (within $3 \%$ ), while the hydrophobic amino acids are able to largely increase the surface tension (up to $24 \%$ ). Interestingly, phenylalanine can form an ordered structure on the droplet surface with the help of $-\mathrm{NH}_{3}^{+}$ and $-\mathrm{COO}^{-}$ions and the phenyl side-chain.

The surface tension of planar liquid-gas interface was also investigated. Due to the limited surface-area-to-volume ratio, a fraction of the hydrophobic amino acid molecules is embedded in the bulk phase and the surface tension is slightly decreased, contrary to the results for droplets. The hydrophilic amino acids are found to somewhat increase the planar surface tension, in agreement with experimental observations. With the computational results of both planar and spherical interfaces, the curvature dependence of the surface tension is modelled by fitting to a quadratic polynomial function of the inverse of droplet radius. The obtained relationship is then used to discuss the indirect effects of amino acids in the framework of Köhler theory. For serine and glycine, the critical supersaturations are both increased after applying the surface tension correction, resulting in slightly better agreement with laboratory measurements. Although this correction is relatively small in the here studied cases, our method provides the possibility of incorporating the curvature dependence of droplet surface tension in atmospheric studies, which could help to improve the accuracy of the Köhler equation in
ACPD

11, 30919-30947, 2011

\section{Amino acids in atmospheric droplets}

X. Li et al.

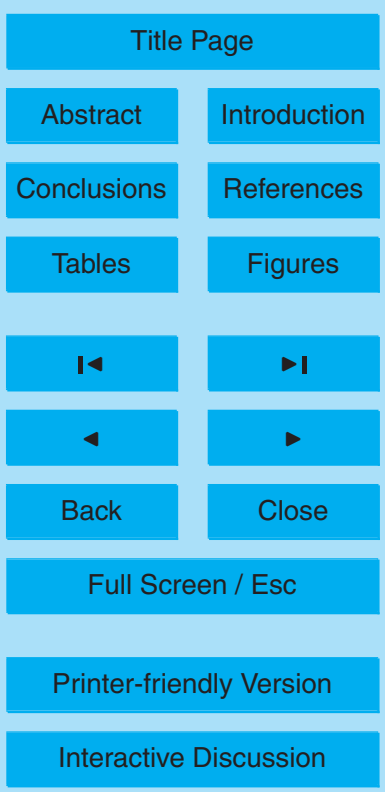


predicting the critical water vapour supersaturation of the activation process of cloud droplets.

Acknowledgements. H. Å. acknowledges a grant from the Swedish Science Research council; "Nucleation, stability and light-absorption of pollutant particles" (contract 2009-3614). The 5 authors also acknowledge a grant from the Swedish Infrastructure Committee (SNIC) for the project "Multiphysics Modeling of Molecular Materials", SNIC 022/09-25.

\section{References}

Alejandre, J., Tildesley, D. J., and Chapela, G. A.: Molecular dynamics simulation of the orthobaric densities and surface tension of water, J. Chem. Phys., 102, 4574-4583, 1995.

Berendsen, H. J. C., Grigera, J. R., and Straatsma, T. P.: The missing term in effective pair potentials, J. Phys. Chem., 91, 6269-6271, 1987.

Bilde, M. and Svenningsson, B.: CCN activation of slightly soluble organics: the importance of small amounts of inorganic salt and particle phase, Tellus B, 56, 128-134, 2004.

Blanchard, D. C.: The oceanic production of volatile cloud nuclei, J. Atmos. Sci., 28, 811-812, 1971

Blanchard, D. C. and Syzdek, L. D.: Film drop production as a function of bubble size, J. Geophys. Res., 93, 3649-3654, 1988.

Bull, H. B. and Breese, K.: A hydrophobicity scale of the amino acid residues, Arch. Biochem. Biophys., 161, 665-670, 1974.

Chen, F. and Smith, P. E.: Simulated surface tensions of common water models, J. Chem. Phys., 126, 221101-1-221101-3, 2007.

Darden, T., York, D., and Pedersen, L.: Particle mesh Ewald: An N-log(N) method for Ewald sums in large systems, J. Chem. Phys., 98, 10089-10092, 1993.

Essmann, U., Perera, L., Berkowitz, M. L., Darden, T., Lee, H., and Pedersen, L. G.: A smooth particle mesh Ewald method, J. Chem. Phys., 103, 8577-8592, 1995.

Facchini, M. C., Mircea, M., Fuzzi, S., and Charlson, R. J.: Cloud albedo enhancement by surface-active organic solutes in growing droplets, Nature, 401, 257-259, 1999.

van Giessen, A. E. and Blokhuis, E. M.: Direct determination of the Tolman length from the bulk pressures of liquid drops via molecular dynamics simulations, J. Chem. Phys., 131, 164705, doi:10.1063/1.3253685, 2009.

\section{Amino acids in atmospheric droplets}

X. Li et al.

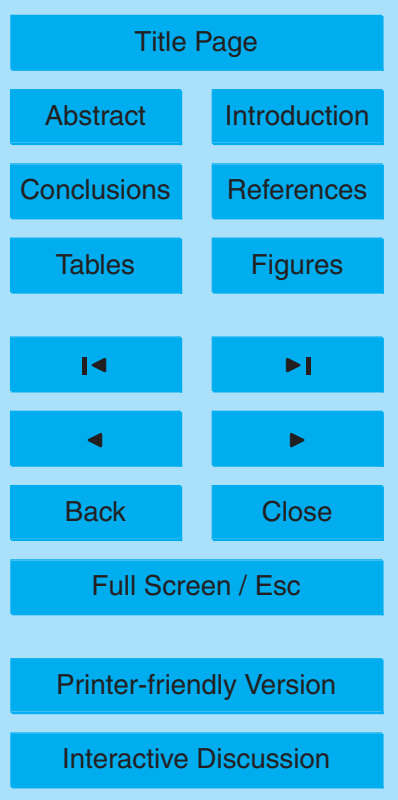


Hess, B.: P-LINCS: A parallel linear constraint solver for molecular simulation, J. Chem. Theory Comput., 4, 116-122, 2008.

Hess, B., Bekker, H., Berendsen, H. J. C., and Fraaije, J. G. E. M.: LINCS: a linear constraint solver for molecular simulations, J. Comput. Chem., 18, 1463-1472, 1997.

5 Hess, B., Kutzner, C., van der Spoel, D., and Lindahl, E.: GROMACS 4: algorithms for highly efficient, load-balanced, and scalable molecular simulation, J. Chem. Theory Comput., 4, 435-447, 2008.

Hoover, W. G.: Canonical dynamics: equilibrium phase-space distributions, Phys. Rev. A, 31, 1695-1697, 1985.

10 Ismail, A. E., Grest, G. S., and Stevens, M. J.: Capillary waves at the liquid-vapor interface and the surface tension of water, J. Chem. Phys., 125, 014702, doi:10.1063/1.2209240, 2006.

Jorgensen, W. L., Maxwell, D. S., and Tirado-Rives, J.: Development and testing of the OPLS all-atom force field on conformational energetics and properties of organic liquids, J. Am. Chem. Soc., 118, 11225-11236, 1996.

Karsten, U., Kirst, G., and Wiencke, C.: Dimethylsulphoniopropionate (DMSP) accumulation in green macioalgae from polar to temperate regions: interactive effects of light versus salinity and light versus temperature, Polar Biol., 12, 603-607, 1992.

Klauda, J. B., Wu, X., Pastor, R. W., and Brooks, B. R.: Long-range Lennard-Jones and electrostatic interactions in interfaces: application of the Isotropic Periodic Sum Method, J. Phys.

$20 \quad$ Chem. B, 111, 4393-4400, 2007.

Kristensson, A., Rosenørn, T., and Bilde, M.: Cloud droplet activation of amino acid aerosol particles, J. Phys. Chem. A, 114, 379-386, 2010.

Kuznetsova, M., Lee, C., and Aller, J.: Characterization of the proteinaceous matter in marine aerosols, Mar. Chem., 96, 359-377, 2005.

Köhler, H.: The nucleus in and the growth of hygroscopic droplets, T. Faraday Soc., 32, 1152$1161,1936$.

Leck, C. and Bigg, E. K.: Aerosol production over remote marine areas - a new route, J. Geophys. Res., 26, 3577-3580, doi:10.1029/1999GL010807, 1999.

Li, X., Hede, T., Tu, Y., Leck, C., and Ågren, H.: Surface-active cis-pinonic acid in atmospheric droplets: a molecular dynamics study, J. Phys. Chem. Lett., 1, 769-773, 2010.

Li, X., Hede, T., Tu, Y., Leck, C., and Ågren, H.: Glycine in aerosol water droplets: a critical assessment of Köhler theory by predicting surface tension from molecular dynamics simulations, Atmos. Chem. Phys., 11, 519-527, doi:10.5194/acp-11-519-2011, 2011.

\section{Amino acids in atmospheric droplets}

X. Li et al.

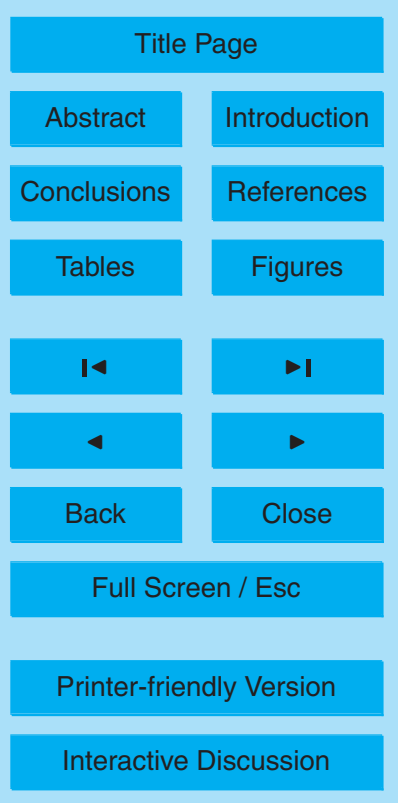


Mace, K. A., Artaxo, P., and Duce, R. A.: Water-soluble organic nitrogen in Amazon Basin aerosols during the dry (biomass burning) and wet seasons, J. Geophys. Res., 108, 4512, doi:10.1029/2003JD003557, 2003a.

Mace, K. A., Duce, R. A., and Tindale, N. W.: Organic nitrogen in rain and aerosol at Cape Grim, 5 Tasmania, Australia, J. Geophys. Res., 108, 4338, doi:10.1029/2002JD003051, 2003b.

Mace, K. A., Kubilay, N., and Duce, R. A.: Organic nitrogen in rain and aerosol in the eastern Mediterranean atmosphere: an association with atmospheric dust, J. Geophys. Res., 108, 4320, doi:10.1029/2002JD002997, 2003c.

Mader, B. T., Yu, J. Z., Xu, J. H., Li, Q. F., Wu, W. S., Flagan, R. C., and Seinfeld, J. H.: Molecular composition of the water-soluble fraction of atmospheric carbonaceous aerosols collected during ACE-Asia, J. Geophys. Res., 109, D06206, doi:10.1029/2003JD004105, 2004.

Mopper, K. and Zika, R. G.: Free amino acids in marine rains: evidence for oxidation and potential role in nitrogen cycling, Nature, 325, 246-249, 1987.

Nosé, S.: A molecular dynamics method for simulations in the canonical ensemble, Mol. Phys., 52, 255-268, 1984.

Pappenheimer, J. R., Lepie, M. P., and Wyman Jr., J.: The surface tension of aqueous solutions of dipolar ions, J. Am. Chem. Soc., 58, 1851-1855, 1936.

Rosenørn, T., Kiss, G., and Bilde, M.: Cloud droplet activation of saccharides and levoglucosan particles, Atmos. Environ., 40, 1794-1802, 2006.

Sampayo, J. G., Malijevský, A., Müller, E. A., de Miguel, E., and Jackson, G.: Communications: evidence for the role of fluctuations in the thermodynamics of nanoscale drops and the implications in computations of the surface tension, J. Chem. Phys., 132, 141101, doi:10.1063/1.3376612, 2010.

Solomon, S., Qin, D., Manning, M., Chen, Z., Marquis, M., Averyt, K. B., Tignor, M., and Miller, H. L. (eds.): Climate Change 2007: The Physical Science Basis Contribution of Working Group I to the Fourth Assessment Report of the Intergovernmental Panel on Climate Change, Cambridge University Press, Cambridge, United Kingdom and New York, NY, USA, 996 pp., 2007.

30 van der Spoel, D., Lindahl, E., Hess, B., van Buuren, A. R., Apol, E., Meulenhoff, P. J., Tieleman, D. P., Sijbers, A. L. T. M., Feenstra, K. A., van Drunen, R., and Berendsen, H. J. C.: Gromacs User Manual version 4.0, www.gromacs.org, last access: 2011-09-05, 2005.

Saxena, V. K.: Evidence of the biogenic nuclei involvement in Antarctic coastal clouds, J. Phys.
ACPD

11, 30919-30947, 2011

\section{Amino acids in atmospheric droplets}

X. Li et al.

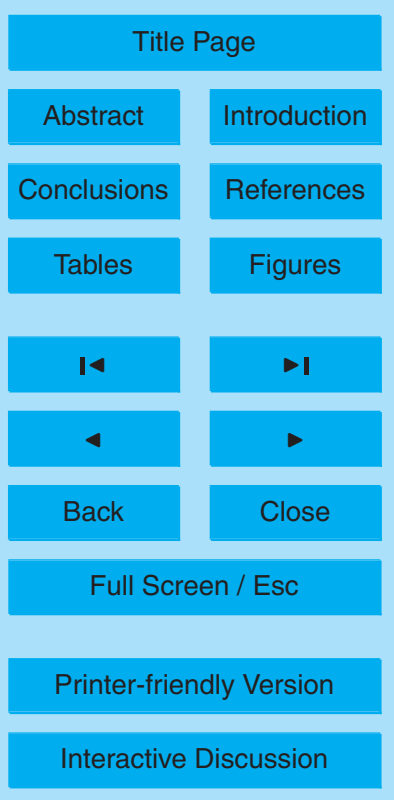

30935 
Chem., 87, 4130-4134, 1983.

Spitzy, A.: Amino acids in marine aerosol and rain, in: Facets of modern biogeochemistry, edited by: Ittekot, V. and Kempe, S., Springer-Verlag, Berlin, Germany, 313-317, 1990.

Thompson, S. M., Gubbins, K. E., Walton, J. P. R. B., Chantry, R. A. R., and Rowlinson, J. S.:

5 A molecular dynamics study of liquid drops, J. Chem. Phys., 81, 530, doi:10.1063/1.447358, 1984.

Twomey, S.: Pollution and the planetary albedo, Atmos. Environ., 8, 1251-1256, 1974.

Wedyan, M. A. and Preston, M. R.: The coupling of surface seawater organic nitrogen and the marine aerosol as inferred from enantiomer-specific amino acid analysis, Atmos. Environ., $10 \quad$ 42, 8698-8705, 2008.

Wine, P. H.: Atmospheric and environmental physical chemistry: pollutants without borders, J. Phys. Chem. Lett., 1, 1749-1751, 2010.

Yeh, I.-C. and Berkowitz, M. L.: Ewald summation for systems with slab geometry, J. Chem. Phys., 111, 3155-3162, 1999.

Yuet, P. K. and Blankschtein, D.: Molecular dynamics simulation study of water surfaces: comparison of flexible water models, J. Phys. Chem. B, 114, 13786-13795, 2010.

Zakharov, V. V., Brodskaya, E. N., and Laaksonen, A.: Surface tension of water droplets: a molecular dynamics study of model and size dependencies, J. Chem. Phys., 107, 1067510683, 1997.

Zhang, Q. and Anastasio, C.: Free and combined amino compounds in atmospheric fine particles $\left(\mathrm{PM}_{2.5}\right)$ and fog waters from Northern California, Atmos. Environ., 37, 2247-2258, 2003.

\section{ACPD}

11, 30919-30947, 2011

\section{Amino acids in atmospheric droplets}

X. Li et al.

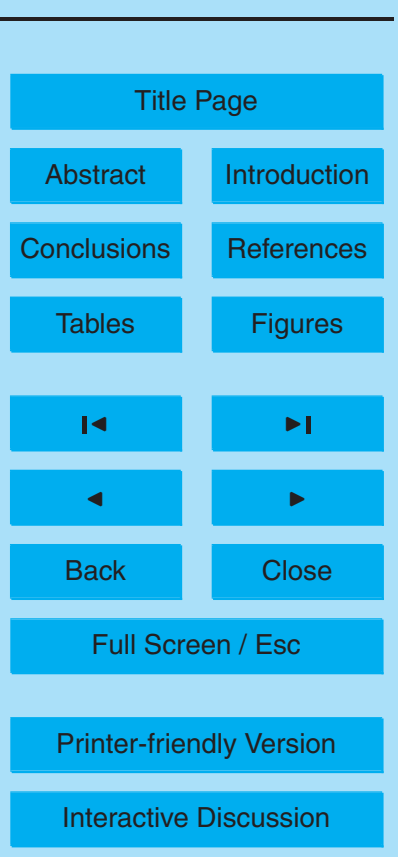




\section{ACPD}

11, 30919-30947, 2011

\section{Amino acids in} atmospheric droplets

X. Li et al.

Table 1. Calculated surface tension-concentration slope for planar liquid-gas interface, together with experimental data. Here $\sigma$ is in $\mathrm{mJ} \mathrm{m}^{-2}$ and $d \sigma / d C$ in $\mathrm{mJ} \mathrm{m}^{-2} \mathrm{Imol}^{-1}$. For pure water, $\sigma$ is equal to $65.63 \mathrm{~mJ} \mathrm{~m}^{-2}$ (Karsten et al., 1992).

\begin{tabular}{lrrrr}
\hline Compound & $\sigma$ & $d \sigma / d C$ & $\begin{array}{r}\text { Pappenheimer } \\
\text { et al. (1936) }\end{array}$ & $\begin{array}{r}\text { Bull and Breese } \\
(1974)\end{array}$ \\
\hline SER & 66.33 & 1.25 & & 0.76 \\
GLY & 66.17 & 0.96 & 0.92 & 1.12 \\
ALA & 67.09 & 2.61 & 0.58 & 0.96 \\
VAL & 64.96 & -1.20 & & -3.74 \\
MET & 65.03 & -1.07 & & -3.01 \\
PHE & 64.01 & -2.89 & & -17.28 \\
\hline
\end{tabular}

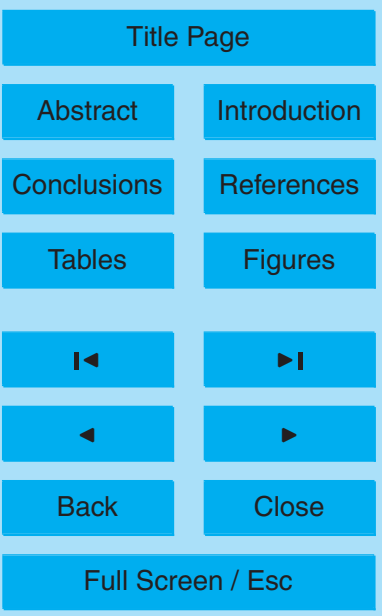

Printer-friendly Version

Interactive Discussion 
ACPD

11, 30919-30947, 2011

\section{Amino acids in \\ X. Li et al.} atmospheric droplets

Table 2. Calculated order parameter of the amino acids in water droplets containing 5000 water molecules.

\begin{tabular}{ll}
\hline Compound & Order parameter \\
\hline SER & 0.0006 \\
GLY & 0.0027 \\
ALA & 0.0145 \\
VAL & 0.4421 \\
MET & 0.4319 \\
PHE & 0.5209 \\
\hline
\end{tabular}

Title Page

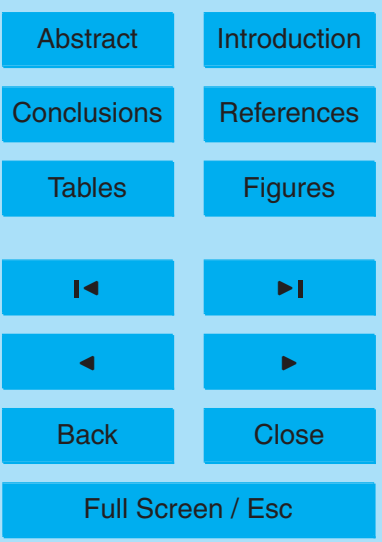

Printer-friendly Version

Interactive Discussion 


\section{ACPD}

11, 30919-30947, 2011

\section{Amino acids in} atmospheric droplets

X. Li et al.

Table 3. Fitted coefficients for quadratic polynomials: $\sigma=c_{0}+c_{1} / R_{\mathrm{e}}+c_{2} / R_{\mathrm{e}}^{2}\left(\sigma\right.$ is in $\mathrm{mJ} \mathrm{m}^{-2}$ and $R_{\mathrm{e}}$ in $\mathrm{nm}$ ).

\begin{tabular}{lrrr}
\hline Compound & $c_{0}$ & $c_{1}$ & $c_{2}$ \\
\hline Water & 65.45 & 50.66 & -100.00 \\
SER & 66.31 & 28.18 & -62.29 \\
GLY & 66.27 & 56.92 & -132.71 \\
ALA & 67.06 & 26.70 & -56.61 \\
VAL & 64.72 & 125.90 & -212.26 \\
MET & 64.77 & 160.73 & -263.97 \\
PHE & 64.15 & 105.15 & -129.33 \\
\hline
\end{tabular}

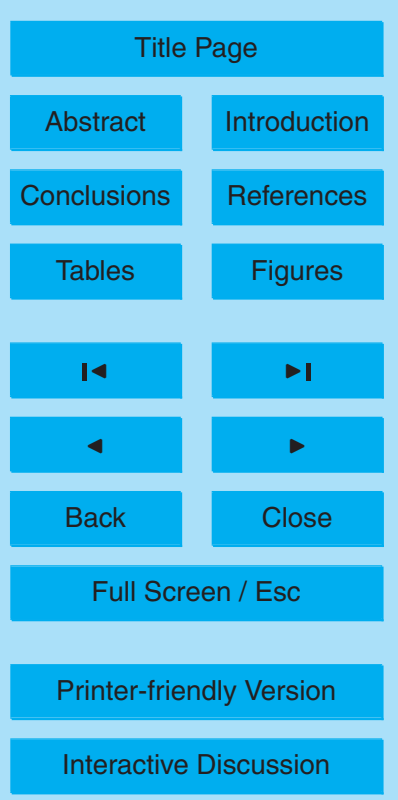




\section{ACPD}

11, 30919-30947, 2011

\section{Amino acids in \\ X. Li et al.} atmospheric droplets

Table 4. Critical supersaturation predicted by Köhler equation without and with surface tension correction.

\begin{tabular}{lccc}
\hline Compound & Original (\%) & Corrected (\%) & Kristensson et al. (2010) \\
\hline SER & 0.658 & 0.667 & $\sim 0.800$ \\
GLY & 0.546 & 0.553 & $\sim 0.650$ \\
ALA & 0.634 & 0.646 & \\
VAL & 0.774 & 0.783 & \\
MET & 0.835 & 0.849 & \\
PHE & 1.150 & 1.163 & \\
\hline
\end{tabular}

Title Page

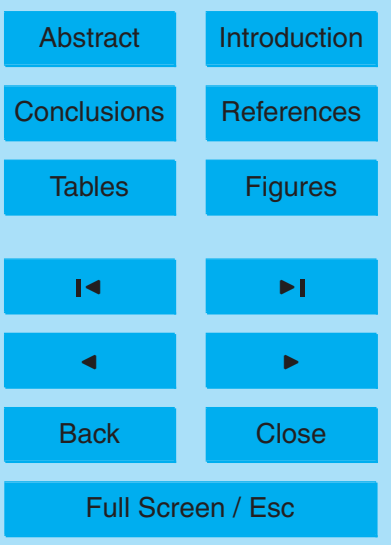

Printer-friendly Version

Interactive Discussion 


\section{ACPD}

11, 30919-30947, 2011

\section{Li et al.}

Amino acids in atmospheric droplets<smiles>[NH3+]CC(=O)O[Na]</smiles><smiles>CC([NH3+])C(=O)[O-]</smiles><smiles>CC(C)C([NH3+])C(=O)[O-]</smiles><smiles>CSCC[C@H]([NH3+])C(=O)[O-]</smiles>

SER

GLY

ALA

VAL

MET

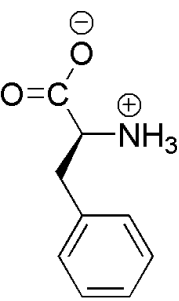

PHE

Fig. 1. Chemical structures of the L-amino acids.

Title Page

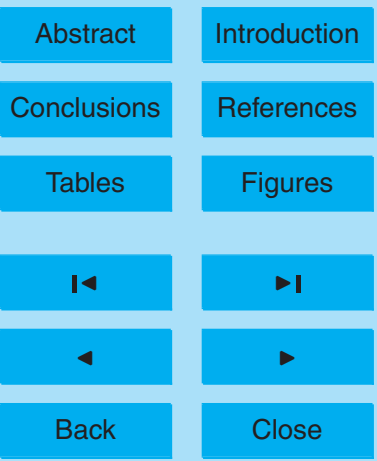

Full Screen / Esc

Printer-friendly Version

Interactive Discussion 


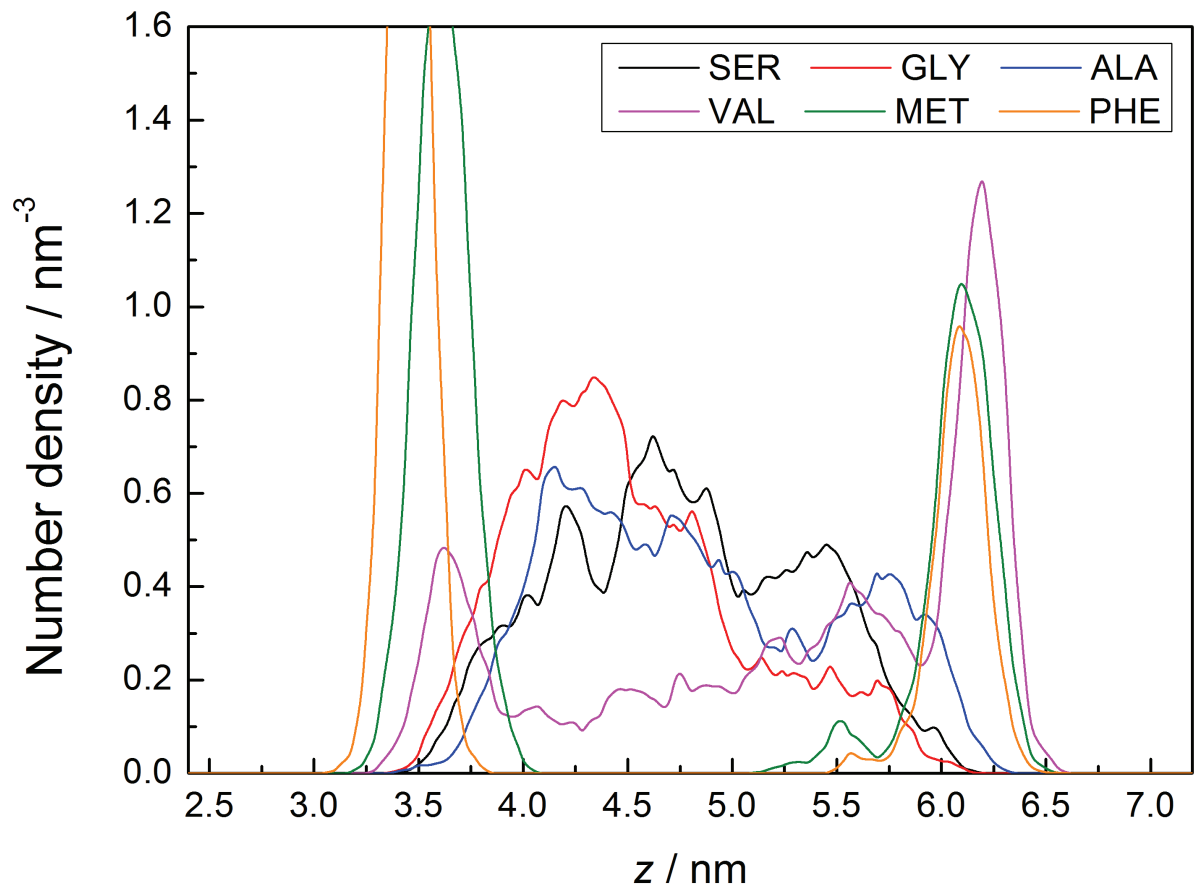

Fig. 2. Axial number densities of the six types of amino acids in planar interface simulations.

\section{ACPD}

11, 30919-30947, 2011

\section{Amino acids in atmospheric droplets}

X. Li et al.

Title Page

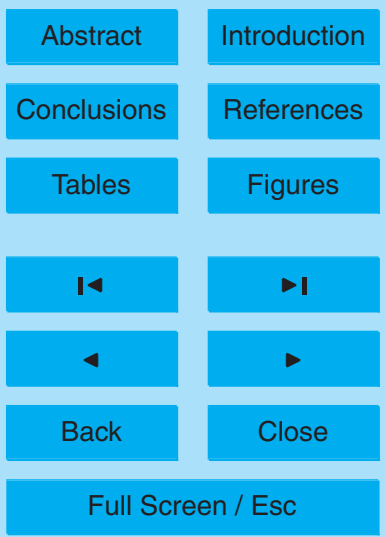

Printer-friendly Version

Interactive Discussion 

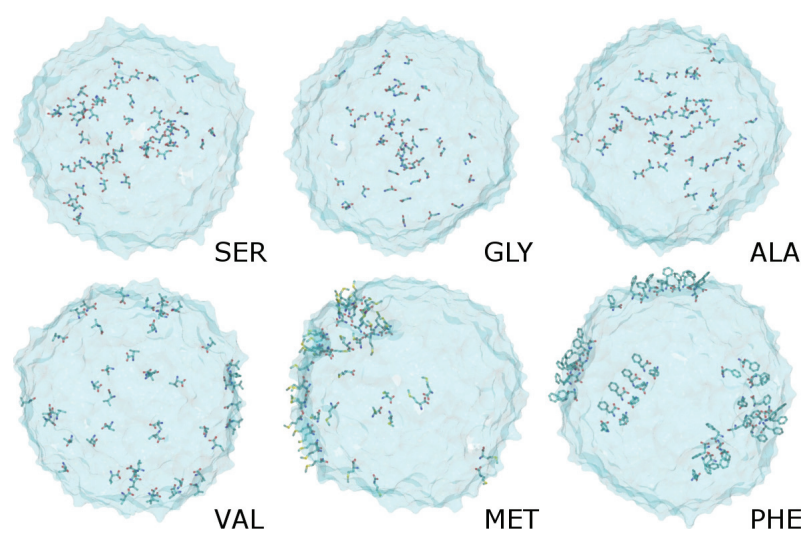

(a)

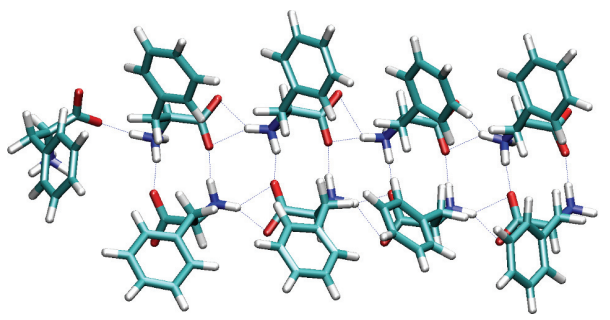

(b)

Fig. 3. (a) Snapshots for water droplets containing different amino acids. (b) Hydrogen bond network in phenylalanine molecules on droplet surface.

\section{ACPD}

11, 30919-30947, 2011

\section{Amino acids in} atmospheric droplets

X. Li et al.

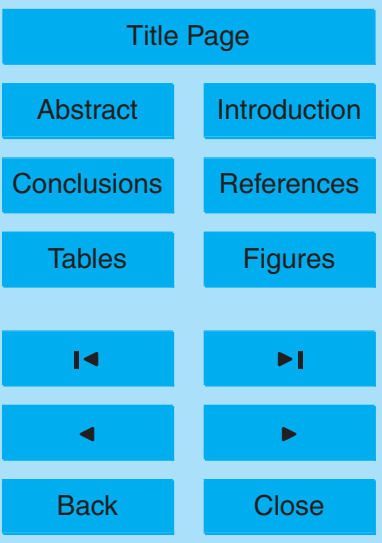

Full Screen / Esc

Printer-friendly Version

Interactive Discussion 


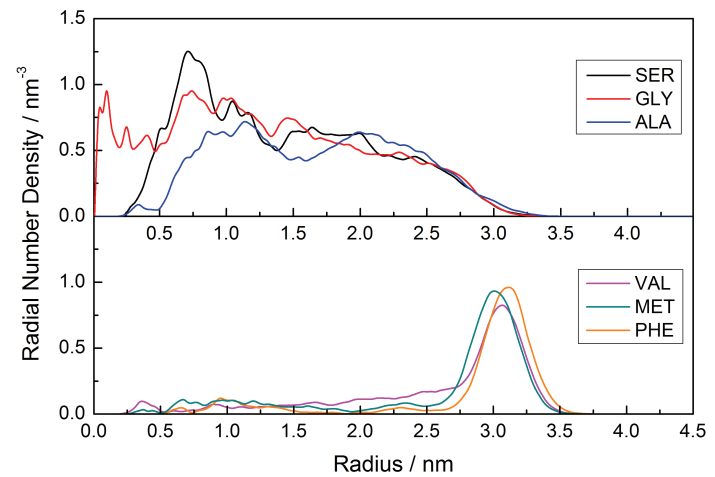

(a)

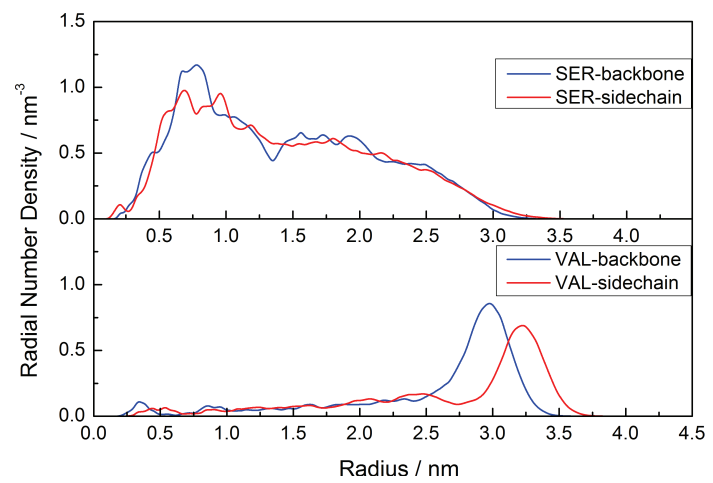

(b)

Fig. 4. (a) Radial number densities of different amino acids in droplets containing 5000 water molecules. (b) Molecular orientation of serine and valine in droplets.

\section{ACPD}

11, 30919-30947, 2011

\section{Amino acids in} atmospheric droplets

X. Li et al.

Title Page

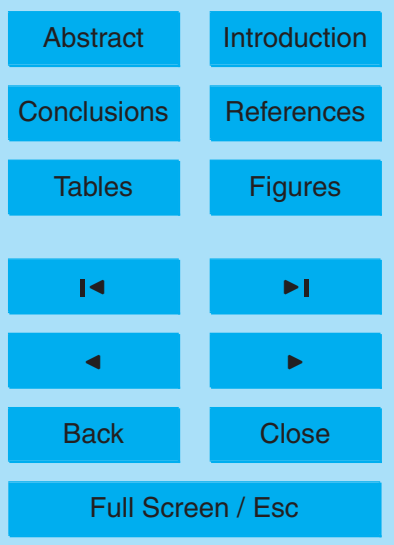

Printer-friendly Version

Interactive Discussion 


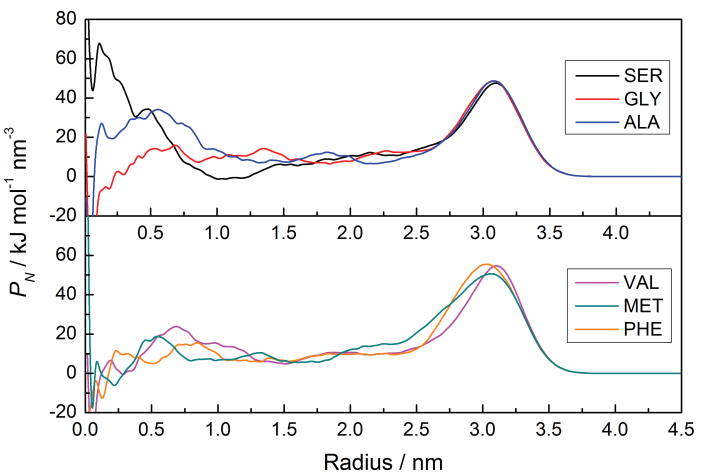

(a)

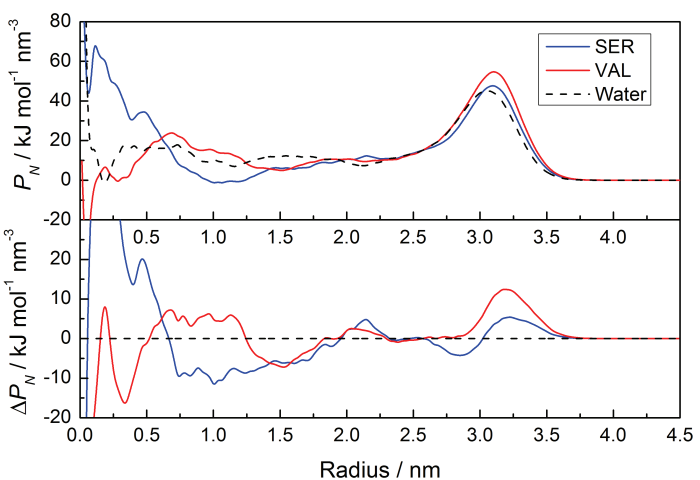

(b)

Fig. 5. (a) Normal components of Irving-Kirkwood pressure tensors in water droplets containing 5000 water molecule and different amino acids. (b) $P_{\mathrm{N}}(r)$ curves for water droplets containing serine and valine in comparison with pure water droplet.

\section{ACPD}

11, 30919-30947, 2011

\section{Amino acids in} atmospheric droplets

X. Li et al.

Title Page

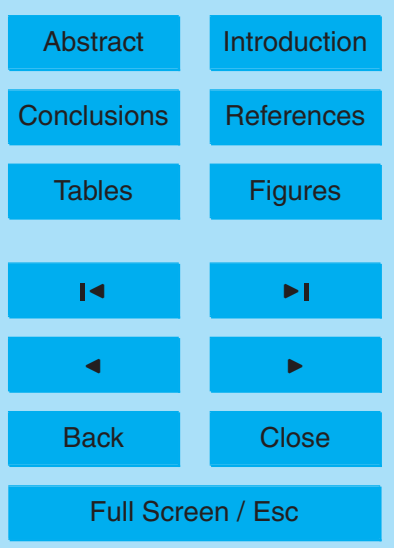

Printer-friendly Version

Interactive Discussion 


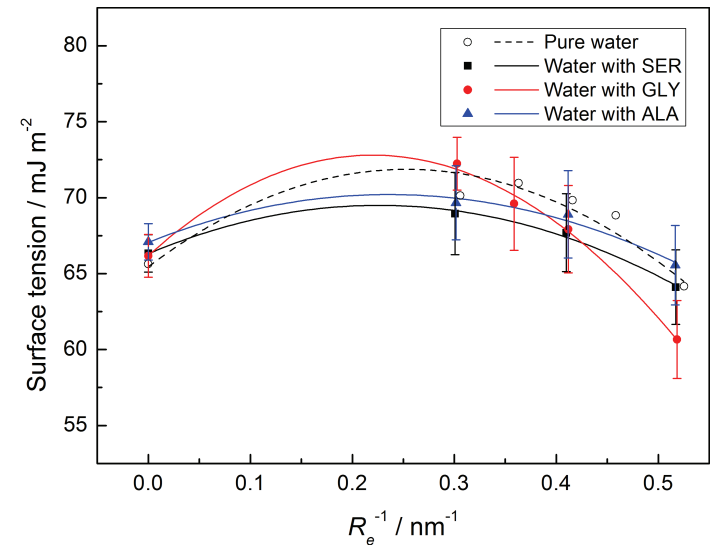

\section{ACPD}

11, 30919-30947, 2011

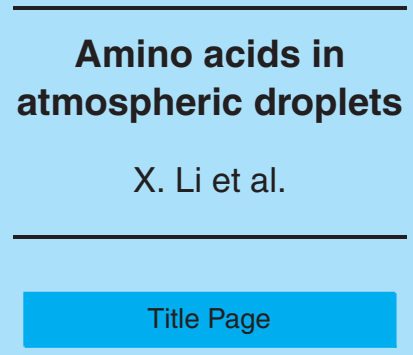

(a)
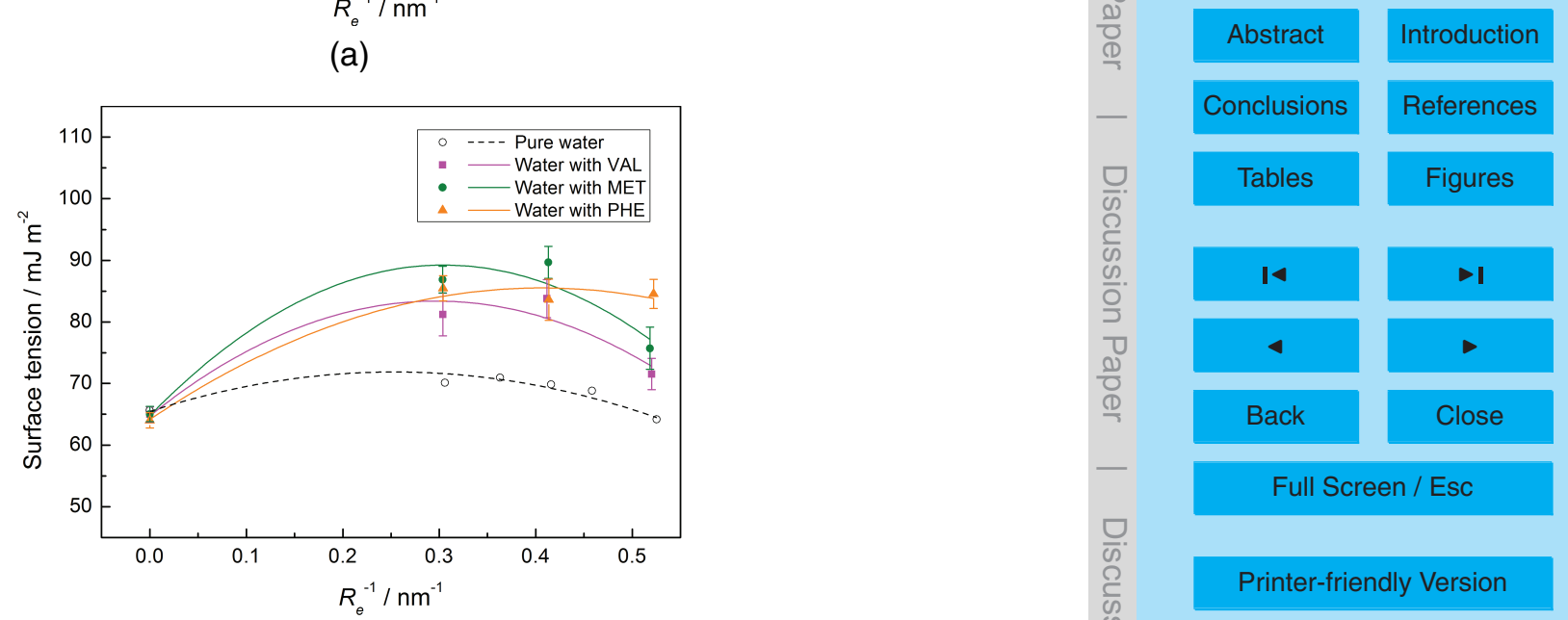

(b)

Fig. 6. Curvature dependence of surface tension of (a) droplet containing hydrophilic amino acid molecules and (b) droplet containing hydrophobic amino acid molecules. 


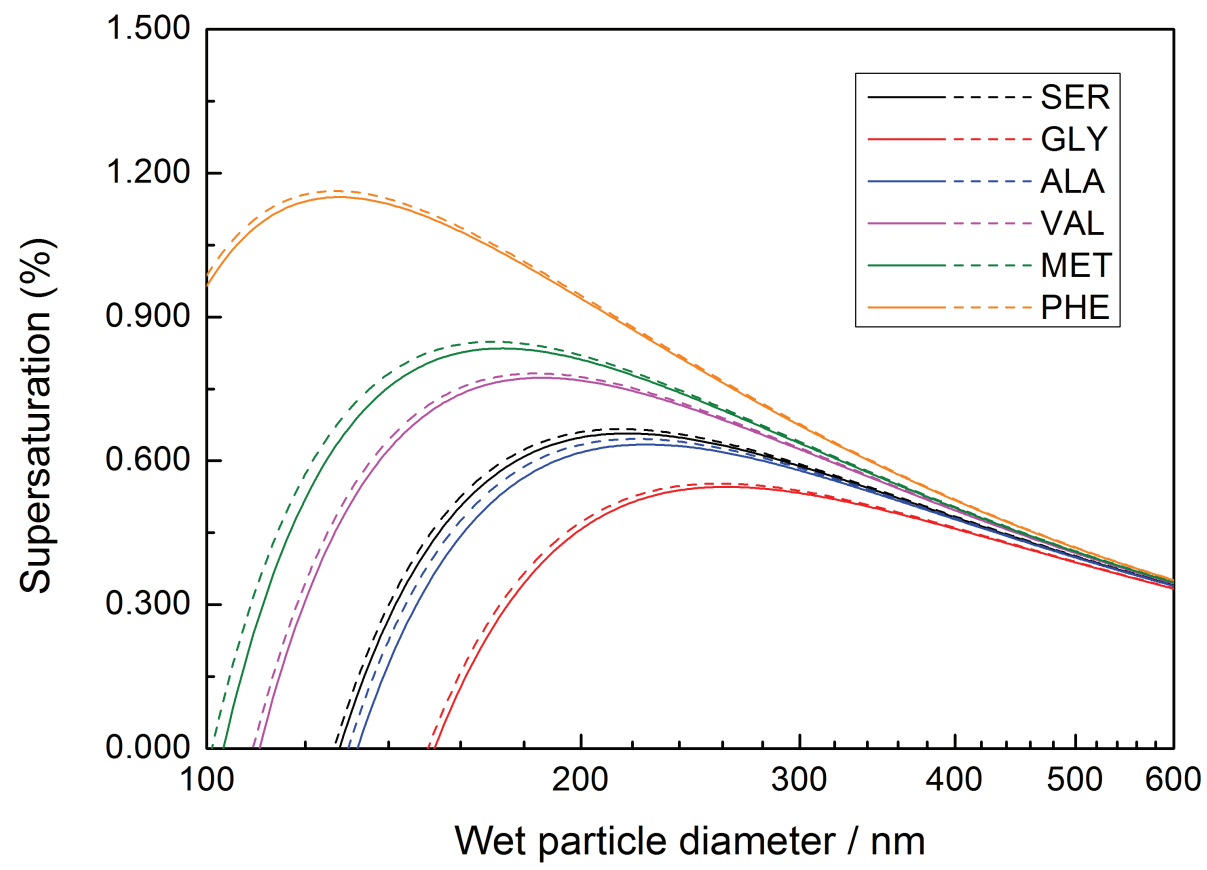

\section{ACPD}

11, 30919-30947, 2011

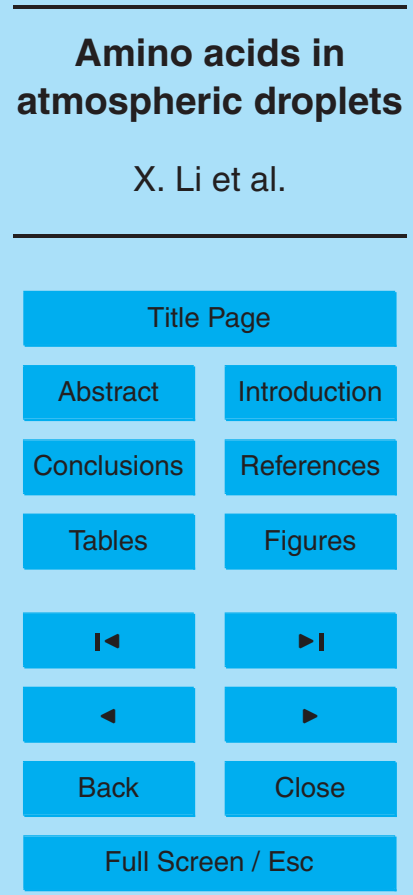

Fig. 7. Original (full lines) and corrected Köhler curves (dashed lines) for the six types of amino acids (dry particle diameter $=50 \mathrm{~nm}$ ).

Printer-friendly Version

Interactive Discussion 